\title{
Investigation of Precipitation Variations over Wet and Dry Areas from Observation and Model
}

\author{
James H. Trammell, ${ }^{1}$ Xun Jiang, ${ }^{1}$ Liming Li, ${ }^{2}$ Maochang Liang, ${ }^{3}$ Mao Li, \\ Jing Zhou, ${ }^{5}$ Eric Fetzer, ${ }^{6}$ and Yuk Yung ${ }^{7}$ \\ ${ }^{1}$ Department of Earth and Atmospheric Sciences, University of Houston, Houston, TX, USA \\ ${ }^{2}$ Department of Physics, University of Houston, Houston, TX, USA \\ ${ }^{3}$ Research Center for Environmental Changes, Academia Sinica, Taipei, Taiwan \\ ${ }^{4}$ Hunan Meteorological Administration, Changsha, China \\ ${ }^{5}$ Department of Physics, Beijing Normal University, Beijing, China \\ ${ }^{6}$ Science Division, Jet Propulsion Laboratory, California Institute of Technology, Pasadena, CA, USA \\ ${ }^{7}$ Division of Geological \& Planetary Sciences, California Institute of Technology, Pasadena, CA, USA \\ Correspondence should be addressed to Xun Jiang; xjiang7@uh.edu
}

Received 25 January 2015; Accepted 22 June 2015

Academic Editor: Ugo Cortesi

Copyright (C) 2015 James H. Trammell et al. This is an open access article distributed under the Creative Commons Attribution License, which permits unrestricted use, distribution, and reproduction in any medium, provided the original work is properly cited.

\begin{abstract}
Our observational study revealed that the precipitation increased over the wet area and decreased over the dry area during the past two decades. Here, we further investigate whether the current atmospheric models can quantitatively capture the characteristics of precipitation from the observation. The NASA Goddard Institute for Space Studies (GISS) model is used to examine the historic simulation of the precipitation, in which the historic greenhouse gases and aerosols are included in the radiative forcing. The consistency between the historic GISS simulation and the Global Precipitation Climatology Project (GPCP) precipitation suggests that the model can qualitatively capture the temporal trends of precipitation over the wet and dry areas. However, the precipitation trends are weaker in the model than in the observation. The observed trends of precipitation do not appear in the control simulation with the fixed concentrations of greenhouse gases and aerosols, which suggests that the global warming due to anthropogenic forcing can influence the temporal variations of precipitation over the wet and dry areas. Diagnostic studies of other variables from the model further suggest that enhanced rising air can increase the precipitation over the wet area.
\end{abstract}

\section{Introduction}

The influence of greenhouse gases on global warming has been investigated in numerous studies [1-3]. This paper focuses on the effect global warming may have on the temporal variation and spatial pattern of precipitation and its possible influence on causing precipitation extremes. Compared with the Clausius-Clapeyron equation relating water vapor to the atmospheric temperature $[4,5]$, there is no simple relationship between precipitation and the atmospheric temperature [6-10]. This is because precipitation is influenced by more factors, such as atmospheric circulation, solar forcing, anthropogenic forcing, and cloud [11, 12]. It is also found that changes in the precipitation can be attributed to natural climate variability and external influences [13]. Most observational studies [7, 10, 14, 15] and climate models [16-18] suggest that global precipitation is increasing more slowly than the total mass of water vapor in response to global warming. Previous studies [10,19-23] try to separate the data into wet versus dry regions; they find that precipitation has an increasing tendency in the wet areas and has a decreasing tendency in dry areas, which is referred to as the "rich-getricher" mechanism. Recently, Chou et al. [24] found that the wet seasons become wetter and dry seasons become dryer. Here, we will investigate whether a current climate model can capture the characteristics of the temporal variations of the precipitation by emphasizing the role of the greenhouse gases and aerosols. Quantitatively simulating the precipitation 
trend will not only help predict the variation of precipitation in the future, but also provide a numerical basis to better understand the physics behind the temporal and spatial variability of precipitation.

\section{Methodology and Data}

Both observations and numerical simulations are employed to examine precipitation under two different regions within $40^{\circ} \mathrm{S}-40^{\circ} \mathrm{N}$ : dry areas with precipitation less than $50 \mathrm{~mm} /$ month and wet areas with precipitation greater than $200 \mathrm{~mm} /$ month. By comparing the current atmospheric model to observations, we can explore how good is the model in simulating precipitation. In addition, a diagnostic analysis of the numerical simulation will be conducted to investigate the physics behind the temporal trends of precipitation over different areas.

We use the NASA Goddard Institute for Space Studies (GISS) model to study the precipitation, temperature, water vapor, and circulation. Specifically, the GISS atmospheric general circulation model coupled to the hybridisopycnic ocean model (HYCOM) [12] is employed. It is an updated version used for IPCC AR4 report [2]. GISSEH Model E20/HYCOM is a $4 \times 5 \times$ L20 model that uses the Model E atmospheric code (internal version number E3), with 20 layers in the vertical, a model top at $0.1 \mathrm{hPa}$, and coupled to the HYCOM ocean model (v. 0.9, $2 \times 2$ $\times$ L16) (http://data.giss.nasa.gov/modelE/ar4/). The atmosphere model includes a gravity-wave drag parameterization in the stratosphere. The HYCOM dynamic ocean model can produce a reasonable magnitude of El Niño Southern Oscillation- (ENSO-) like variability [12]. This model has been utilized to study the influence of solar and anthropogenic forcing on the tropical hydrology [12] and explore the climate drift on twenty-first-century projection [25]. The control simulation starts with year 1850 atmospheric conditions containing fixed greenhouse gases and aerosols. The historic model simulation includes the historic greenhouse gases and aerosols changes in the radiative forcing.

The observational studies of precipitation are based on the data sets from the Global Precipitation Climatology Project (GPCP), which is an international project to construct the global long-term record of precipitation over the whole world on behalf of the World Meteorological Organization (WMO), the World Climate Research Programme (WCRP), and the Global Energy and Water Experiment (GEWEX) [26]. There are many investigators and organizations contributing to this project $[14,26]$. The data sets of precipitation from the latest version of the GPCP (i.e., Version 2.2) are available on the public websites maintained by the Physical Sciences Division (PSD) of the Earth System Research Laboratory (ESRL) in the National Oceanic \& Atmospheric Administration (NOAA) (http://www.esrl.noaa.gov/psd/data/gridded/data.gpcp.html). GPCP Version 2.2 precipitation data are derived from satellite and gauge measurements. It incorporates data from SSM/I emission estimates, F17 SSMIS, SSM/I scattering estimates, GPI and OPI estimates and rain gauge analysis, and TOVS estimates [27]. The spatial resolution of GPCP V2.2 precipitation is $2.5^{\circ} \times 2.5^{\circ}$ (latitude by longitude). Analyses

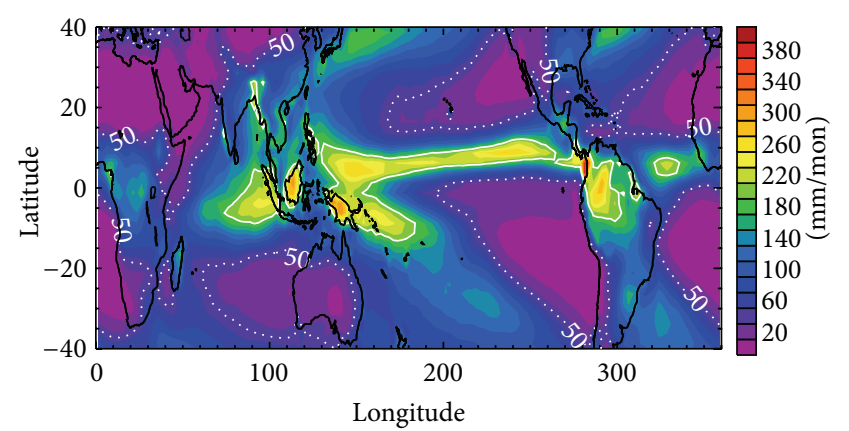

(a) GPCP Precipitation Climatology

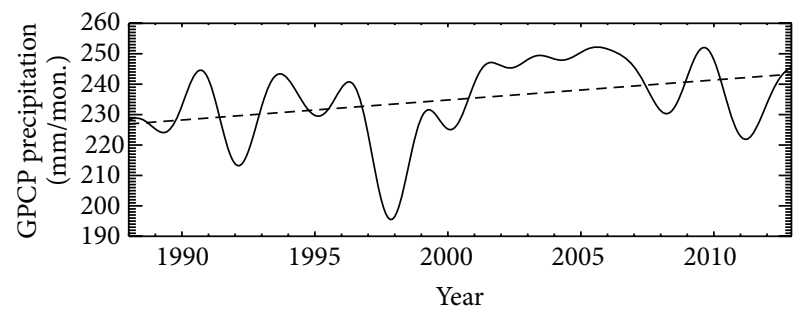

(b) $P>200 \mathrm{~mm} / \mathrm{mon}$.

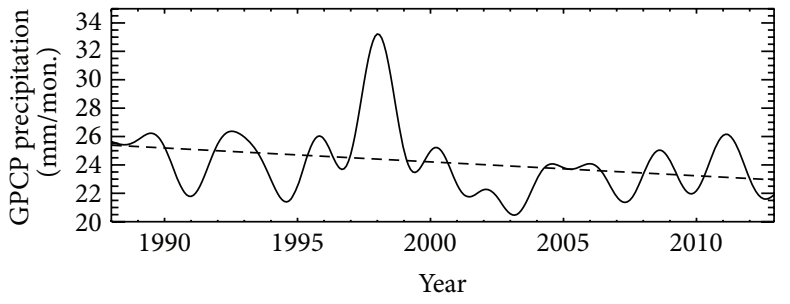

(c) $P<50 \mathrm{~mm} / \mathrm{mon}$.

FIGURE 1: (a) Spatial pattern of the mean GPCP V2.2 precipitation $(P)$ for $1988-2012$ over the tropical and subtropical regions $\left(40^{\circ} \mathrm{S}-\right.$ $40^{\circ} \mathrm{N}$ ). (b) Low-pass filtered time series of precipitation averaged over high-precipitation areas $(P>200 \mathrm{~mm} / \mathrm{mon}$.). (c) Low-pass filtered time series of precipitation averaged over low-precipitation areas $(P<50 \mathrm{~mm} / \mathrm{mon}$.). El Niño Southern Oscillation (ENSO) signals have been removed from the time series by a regression method based on the Niño3.4 index. A low-pass filter is also applied to remove the high frequency signals. Solid white contours refer to the wet area where the precipitation is higher than $200 \mathrm{~mm} / \mathrm{mon}$. Dotted white contours refer to the dry area where the precipitation is lower than $50 \mathrm{~mm} / \mathrm{mon}$.

based on the observational data sets are conducted to examine the consistency between the historic simulation and the observational study from 1988 to 2012, where GPCP data overlap with Special Sensor Microwave Imager data and are believed to be more reliable [28].

\section{Results}

The spatial pattern of the observed climatological GPCP V2.2 precipitation for 1988-2012 is shown in Figure 1(a). The highprecipitation and low-precipitation areas are defined as the areas with climatological monthly mean precipitation larger than 200 millimeter per month ( $\mathrm{mm} / \mathrm{mon}$.) and less than $50 \mathrm{~mm} / \mathrm{mon}$., respectively. The high-precipitation areas and 
TABLE 1: Trends for precipitation $(P)$, column water $(W)$, temperature $(T)$, and vertical pressure velocity $(\Omega)$ over wet area $(P>200 \mathrm{~mm} / \mathrm{mon}$. $)$ and dry area $(P<50 \mathrm{~mm} / \mathrm{mon}$. $)$.

\begin{tabular}{|c|c|c|}
\hline & Wet area $(P>200 \mathrm{~mm} / \mathrm{mon})$. & Dry area $(P<50 \mathrm{~mm} / \mathrm{mon})$. \\
\hline GPCP $P$ & $6.57 \pm 0.27 \mathrm{~mm} / \mathrm{mon} . /$ decade & $-0.98 \pm 0.23 \mathrm{~mm} / \mathrm{mon} . /$ decade \\
\hline GISS $P$ (control simulation) & $0.02 \pm 0.19 \mathrm{~mm} / \mathrm{mon} . /$ decade & $-0.03 \pm 0.24 \mathrm{~mm} / \mathrm{mon} . / \mathrm{decade}$ \\
\hline GISS $P$ (historic simulation) & $3.8 \pm 0.17 \mathrm{~mm} / \mathrm{mon} . /$ decade & $-0.48 \pm 0.21 \mathrm{~mm} / \mathrm{mon} . / \mathrm{dec}$ ade \\
\hline GISS $W$ (control simulation) & $-0.06 \pm 0.18 \mathrm{~mm} / \mathrm{mon} . / \mathrm{dec} a d e$ & $0.057 \pm 0.20 \mathrm{~mm} / \mathrm{mon} . / \mathrm{dec}$ ade \\
\hline GISS $W$ (historic simulation) & $1.15 \pm 0.21 \mathrm{~mm} / \mathrm{mon} . /$ decade & $0.49 \pm 0.20 \mathrm{~mm} / \mathrm{mon} . / \mathrm{dec}$ de \\
\hline GISS T (control simulation) & $-0.04 \pm 0.19^{\circ} \mathrm{C} /$ decade & $-0.04 \pm 0.20^{\circ} \mathrm{C} /$ decade \\
\hline GISS T (historic simulation) & $0.61 \pm 0.23^{\circ} \mathrm{C} /$ decade & $0.52 \pm 0.22^{\circ} \mathrm{C} /$ decade \\
\hline GISS $\Omega$ (control simulation) & $-0.016 \pm 0.17 \mathrm{~Pa} /$ day/decade & $-0.04 \pm 0.18 \mathrm{~Pa} /$ day/decade \\
\hline GISS $\Omega$ (historic simulation) & $-0.32 \pm 0.18 \mathrm{~Pa} /$ day/decade & $-0.03 \pm 0.21 \mathrm{~Pa} /$ day/decade \\
\hline
\end{tabular}

low-precipitation areas are highlighted by the solid white contours and dotted white contours in Figure 1(a). Figure 1(a) illustrates that the high-precipitation area is roughly the same as the Intertropical Convergence Zone (ITCZ) identified by the highly reflective clouds [29]. The low-precipitation area comprises most of the other regions in the tropics and midlatitudes. Two different approaches were attempted when evaluating these data in preparation for plotting a time series. Since the ITCZ fluctuates in position throughout the year, one way to prepare the data is to allow the wet and dry areas to change position with month to follow the movement of the ITCZ. Another way is to calculate the precipitation over the climatological wet and dry areas as shown in Figure 1(a). Both approaches yielded similar results. Time series of the observed precipitation over the climatological wet and dry areas are plotted in Figures 1(b) and 1(c), which include data over both land and ocean between $40^{\circ} \mathrm{S}$ and $40^{\circ} \mathrm{N}$. From this temporal variation of precipitation, it is evident that the areas already receiving great precipitation tend to receive more while the areas already receiving little precipitation tend to receive less. The trend and uncertainty associated with the wet area are $6.57 \pm 0.27 \mathrm{~mm} / \mathrm{mon}$./decade while for the dry area are $-0.98 \pm 0.23 \mathrm{~mm} / \mathrm{mon}$./decade. Details for trends are listed in Table 1. El Niño Southern Oscillation (ENSO) signals have been removed from the precipitation time series at each location by a multiple regression method to avoid large biases in the trend due to significant interannual variability. We first regress the original time series on first, second, and third Legendre polynomials, annual cycle, semiannual cycle, and ENSO signal [30]. Then we subtract the ENSO signal from the original time series. Also applied to the data was a 20-month low-pass filter to remove the high frequency signals. The low-pass filter is constructed as a convolution of a step function with a Hanning window and chosen to obtain a full signal from periods above 20 months [31]. The linear trend coefficient for the time series is calculated from the least-square fitting. The standard error of the linear trend is estimated by $\operatorname{SE}(b)=\left(\sigma / \sqrt{N_{1}}\right) / \sqrt{\left(1 / N_{2}\right) \sum x_{i}^{2}}$ [32], where $\sigma$ is the standard deviation of the data, $N_{1}$ is the number of degrees of freedom of the data, $N_{2}$ is the length of the data set, and $x_{i}$ is the time series corresponding to a number of measurements with $\sum x_{i}=0$. The number of degrees of freedom $N_{1}$ is estimated by a formula
$N_{1}=N_{2}\left[1-r(\Delta x)^{2}\right] /\left[1+r(\Delta x)^{2}\right]$ suggested by Bretherton et al. [33], where $r(\Delta x)$ is the autocorrelation corresponding to a lag of time interval $\Delta x$.

Next, we use the NASA GISS/HYCOM model to investigate whether the model can capture the overall trends seen in the observations and reproduce the characteristics of precipitation. We conduct experimental simulations in a control simulation where the greenhouse gases and aerosols are fixed and a historic simulation where the historic greenhouse gases and aerosols are included. Figure 2 illustrates the identified areas of high and low precipitation and contains each of their precipitation trends for both the control and historic simulations. Corresponding trends and uncertainties in the control simulation for the wet area are $0.02 \pm 0.19 \mathrm{~mm} / \mathrm{mon}$./decade with $-0.03 \pm 0.24 \mathrm{~mm} / \mathrm{mon}$./decade for the dry area, as shown in Figures 2(a) and 2(c). There is no significant trend in the precipitation over the wet and dry areas when the greenhouse gas concentrations and aerosols are fixed. In contrast, the historic simulation demonstrates trends of $3.8 \pm$ $0.17 \mathrm{~mm} / \mathrm{mon}$./decade and $-0.48 \pm 0.21 \mathrm{~mm} / \mathrm{mon}$./decade for the wet and dry areas, respectively, as shown in Figures 2(b) and $2(\mathrm{~d})$. The trends $(3.8 \pm 0.17 \mathrm{~mm} / \mathrm{mon}$./decade and $-0.48 \pm 0.21 \mathrm{~mm} / \mathrm{mon}$./decade) in the GISS precipitation are smaller than those seen in the observations (Figures 1(b) and $1(\mathrm{c})$ ), which might be related to the weakness of the model in simulating the Pacific decadal variability (PDV). As suggested by Gu and Adler [34], the PDV can also contribute to the long-term trend of precipitation in addition to global warming. The GISS/HYCOM model cannot simulate the PDV well, which might contribute to the weak trends in the model precipitation. We also apply similar analyses to AMIPtype CMIP5 model simulations and obtain similar results. Since most CMIP5 model simulations end at 2008 and have shorter time periods than those of observations, we do not include results from these models in this paper.

The concentration of water vapor is one factor that can influence precipitation. Figure 3 illustrates the trends of column water for both the historic and control simulations in the wet and dry areas. Corresponding trends in the control simulation for the wet area are $-0.06 \pm 0.18 \mathrm{~mm} /$ mon./decade with $0.057 \pm 0.20 \mathrm{~mm} / \mathrm{mon}$./decade for the dry area. Column water trends for the historic simulation are $1.15 \pm 0.21 \mathrm{~mm} / \mathrm{mon}$./decade over the wet area with $0.49 \pm 0.20 \mathrm{~mm} / \mathrm{mon}$./decade for the dry area, as shown in 


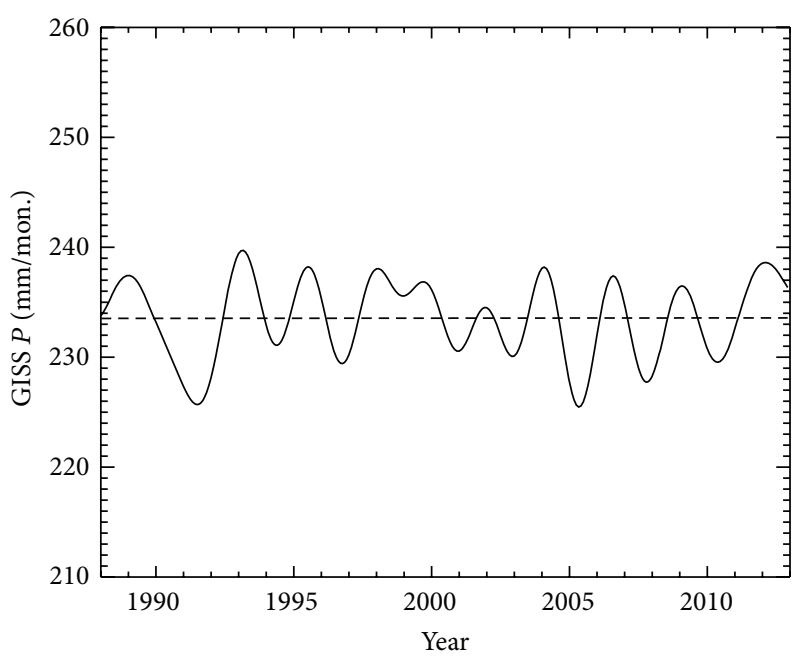

(a) $P>200 \mathrm{~mm} / \mathrm{mon}$.

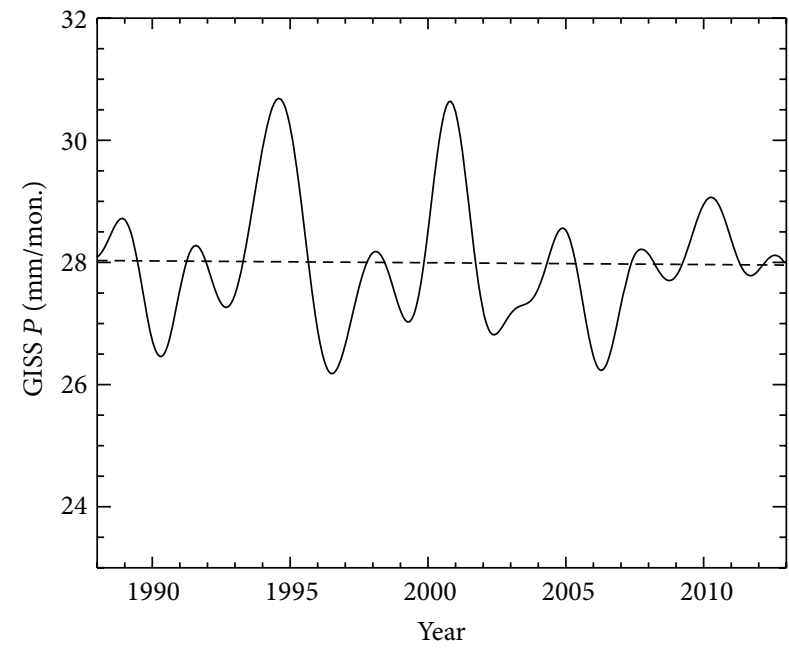

(c) $P<50 \mathrm{~mm} / \mathrm{mon}$.

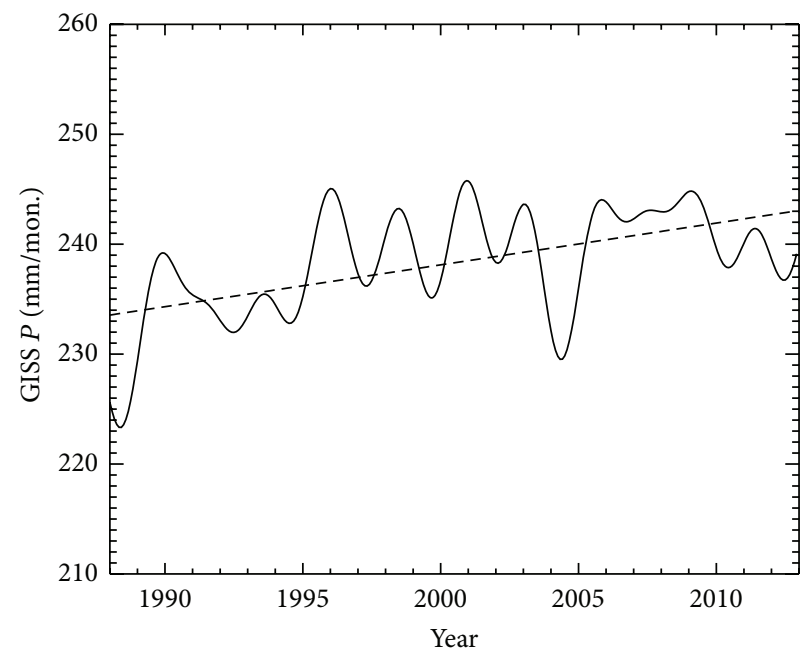

(b) $P>200 \mathrm{~mm} / \mathrm{mon}$.

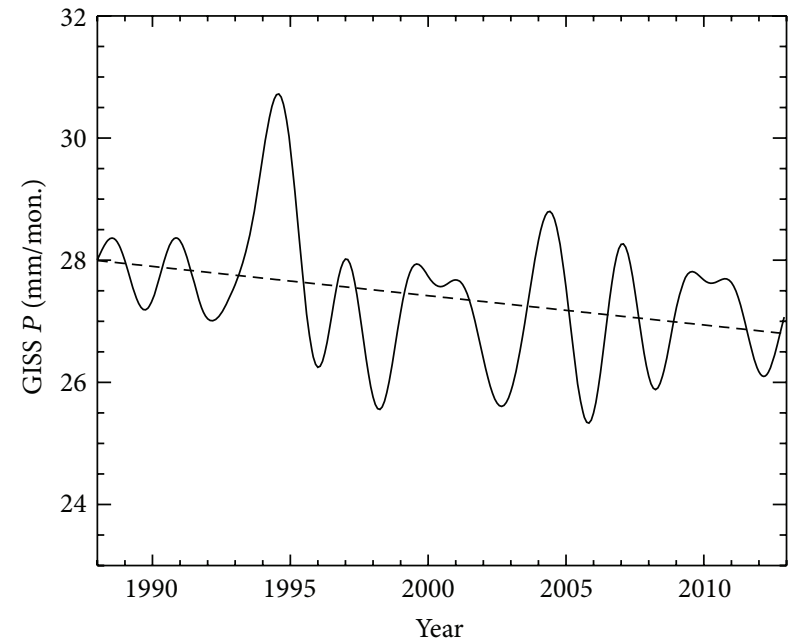

(d) $P<50 \mathrm{~mm} / \mathrm{mon}$.

Figure 2: Low-pass filtered time series for precipitation $(P)$ from GISS/HYCOM. (a) $P$ over high-precipitation area $(P>200 \mathrm{~mm} / \mathrm{mon}$. $)$ from the control simulation (solid line) and trend (dashed line). (b) $P$ over high-precipitation area from the historic simulation (solid line) and trend (dashed line). (c) Same as (a) except for areas with precipitation $<50 \mathrm{~mm} / \mathrm{mon}$. (d) Same as (b) except for areas with precipitation $<50 \mathrm{~mm} / \mathrm{mon}$.

Figures 3(b) and 3(d). The historic simulation exhibits a strong positive trend for both the wet and dry areas while the control simulation reveals virtually no trend in either. Furthermore, of considerable note is the strength of the trend in column water in the historic simulation and the models ability to simulate it with low uncertainties and small deviations.

The concentration of water vapor is related to the atmospheric temperature by the Clausius-Clapeyron equation [35]. Therefore, we further examine the temporal variation of atmospheric temperature from the simulations by the GISS model. Results of the GISS $337 \mathrm{hPa}$ temperature averaged in the identified areas of high and low precipitation are shown in Figure 4 for both the historic and control simulations. Corresponding trends and uncertainties in the control simulation for the wet area are $-0.04 \pm 0.19^{\circ} \mathrm{C} /$ decade with $-0.04 \pm 0.20^{\circ} \mathrm{C} /$ decade for the dry area. Trends for the $337 \mathrm{hPa}$ temperature in the historic simulation are $0.61 \pm$ $0.23^{\circ} \mathrm{C} /$ decade over the wet area and $0.52 \pm 0.22^{\circ} \mathrm{C} /$ decade over the dry area, as illustrated in Figures 4(b) and 4(d). Temperature has positive trends over both wet areas and dry areas, which are responses to the anthropogenic forcing in the historic simulation. According to the Clausius-Clapeyron law, air with high temperature will hold more water vapor. Column water vapor also shows positive trends in both the wet and dry areas in Figure 3. This behavior is different from the temporal variation of precipitation for wet and dry areas.

To better understand the possible physics in the temporal variation of precipitation, we examine the vertical pressure velocity $\Omega=d P / d t$ in the GISS model over the wet and dry areas. Results for $\Omega$ at $337 \mathrm{hPa}$ are given in Figure 5 . Corresponding trends in the control simulation for the wet 


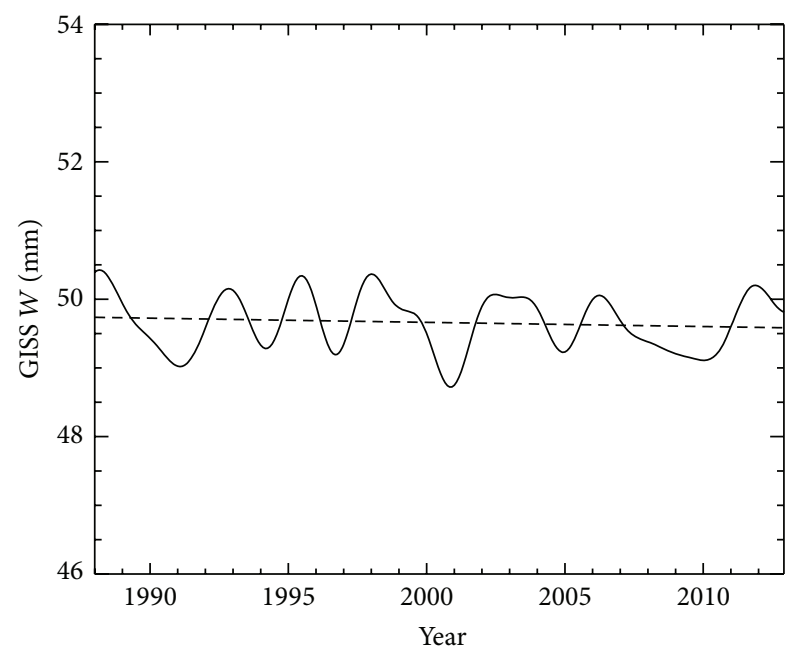

(a) $P>200 \mathrm{~mm} / \mathrm{mon}$.

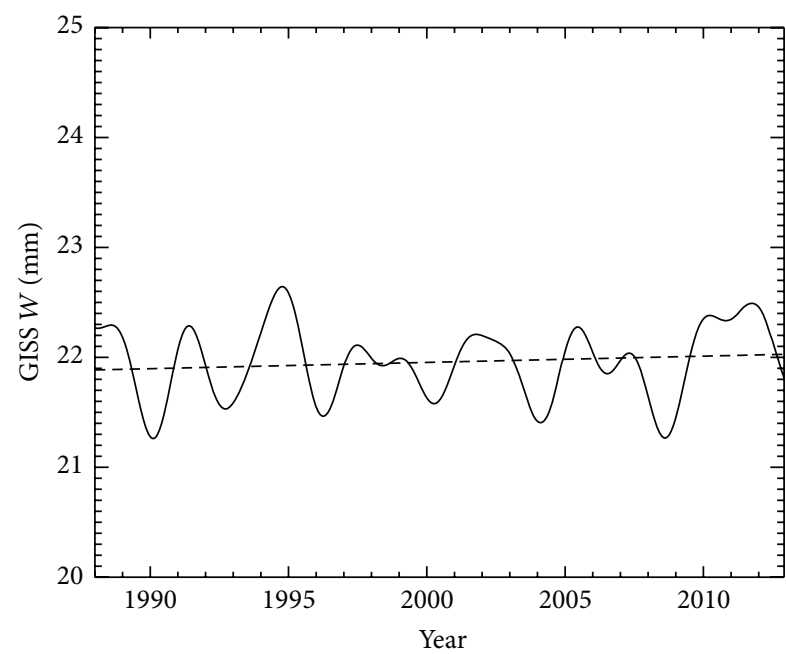

(c) $P<50 \mathrm{~mm} / \mathrm{mon}$

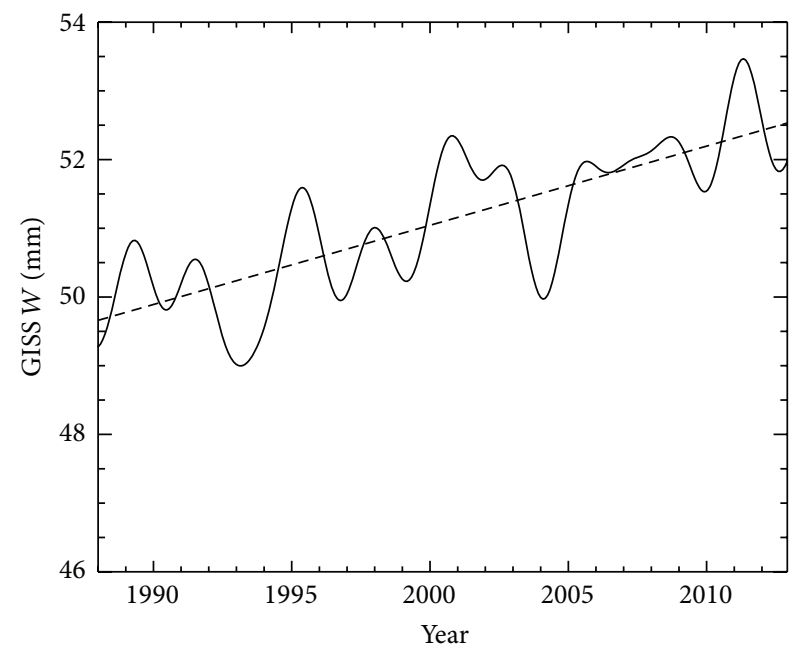

(b) $P>200 \mathrm{~mm} / \mathrm{mon}$.

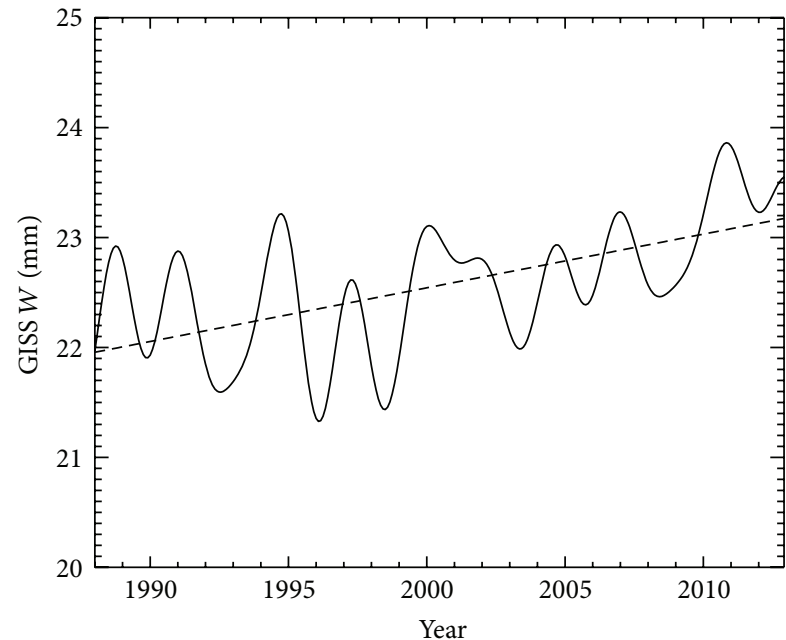

(d) $P<50 \mathrm{~mm} / \mathrm{mon}$

FIGURE 3: Low-pass filtered time series for column water vapor $(W)$ from GISS/HYCOM. (a) $W$ over high-precipitation area $(P>$ $200 \mathrm{~mm} / \mathrm{mon}$.) from the control simulation (solid line) and trend (dashed line). (b) $W$ over high-precipitation area from the historic simulation (solid line) and trend (dashed line). (c) Same as (a) except for areas with precipitation $<50 \mathrm{~mm} / \mathrm{mon}$. (d) Same as (b) except for areas with precipitation $<50 \mathrm{~mm} / \mathrm{mon}$.

area are $-0.016 \pm 0.17 \mathrm{~Pa} /$ day/decade with $-0.04 \pm 0.18 \mathrm{~Pa} /$ day/decade for the dry area. Trends for the $337 \mathrm{hPa} \Omega$ in the historic simulation are $-0.32 \pm 0.18 \mathrm{~Pa} / \mathrm{day} /$ decade over the wet area and $-0.03 \pm 0.21 \mathrm{~Pa} /$ day/decade over the dry area, as demonstrated in Figures 5(b) and 5(d). Figure 5(b) illustrates a significant negative trend in the $337 \mathrm{hPa}$ vertical pressure velocity. This negative trend suggests that the rising air is strengthening over the wet area and, in turn, can lead to enhanced precipitation there. The temporal variation of the vertical pressure velocity is consistent with a mechanism suggested in some previous studies $[19,21]$, in which the gross moist stability of the atmospheric boundary layer is reduced due to increased moisture and hence the convection and the related precipitation are amplified. Our investigation of the column water vapor and temperature suggests positive trends of column water vapor and temperature over the dry area.
Furthermore, the GISS historic simulation suggests that the vertical pressure velocity did not significantly change during the past two decades over the dry areas. The temporal trend of the precipitation over the dry area poses a challenge to our current understanding, which will be explored in the future.

The GISS/HYCOM model is also utilized to examine the temporal variation of residual meridional circulations. To explore the influence of anthropogenic forcing on the meridional circulation, we calculated the time series of $337 \mathrm{hPa}$ residual vertical velocity [31] over $15^{\circ} \mathrm{N}-15^{\circ} \mathrm{S}$ from the GISS/HYCOM control and historic simulations. Results are shown in Figure 6. In general, the increasing precipitation over the ITCZ area (i.e., rich-get-richer) is accompanied by an intensifying convection over the tropical region. This intensifying convection can be seen by the increasing trend of residual vertical velocity shown in Figure 6(a) of 


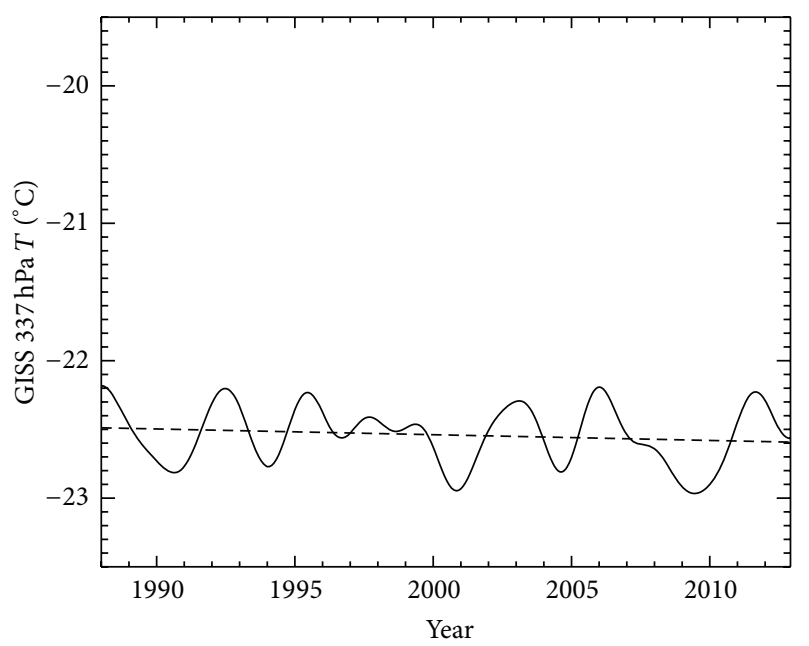

(a) $P>200 \mathrm{~mm} / \mathrm{mon}$.

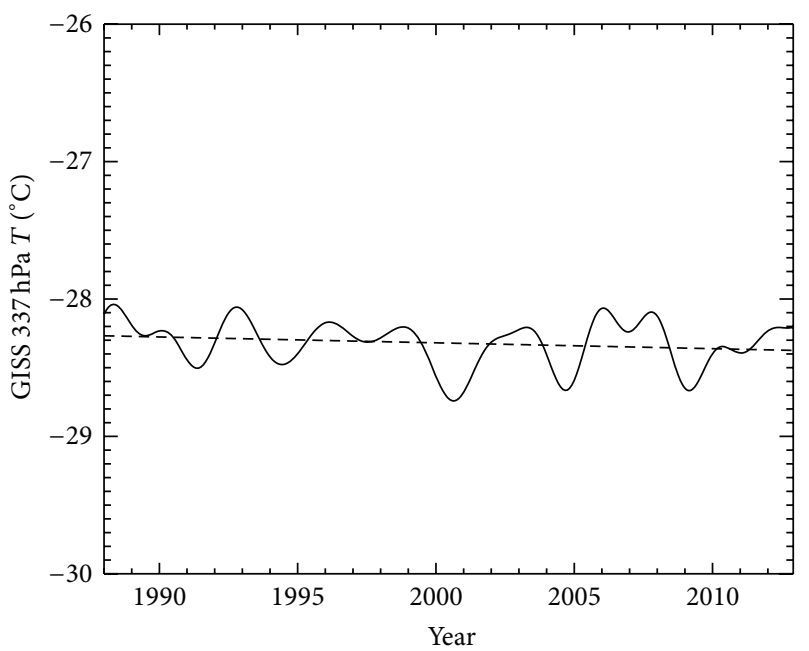

(c) $P<50 \mathrm{~mm} / \mathrm{mon}$.

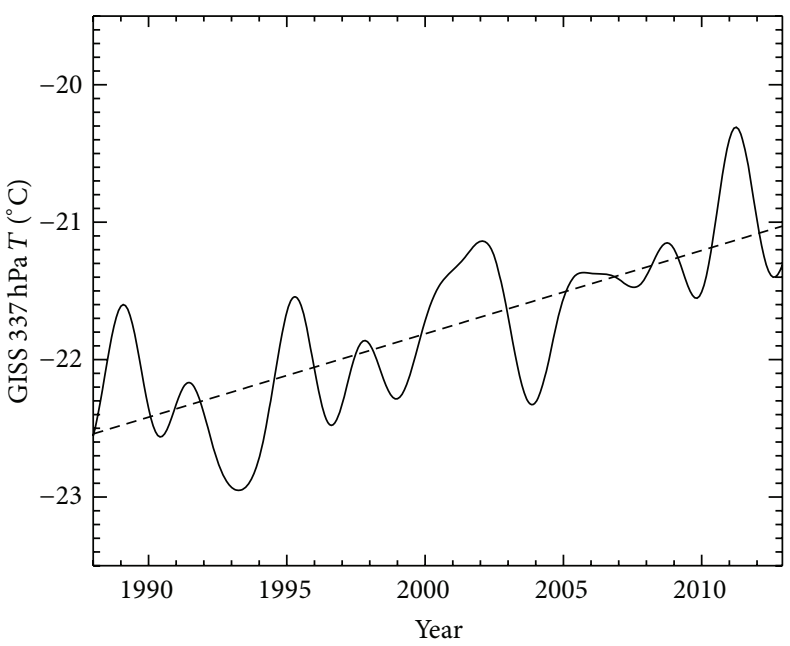

(b) $P>200 \mathrm{~mm} / \mathrm{mon}$.

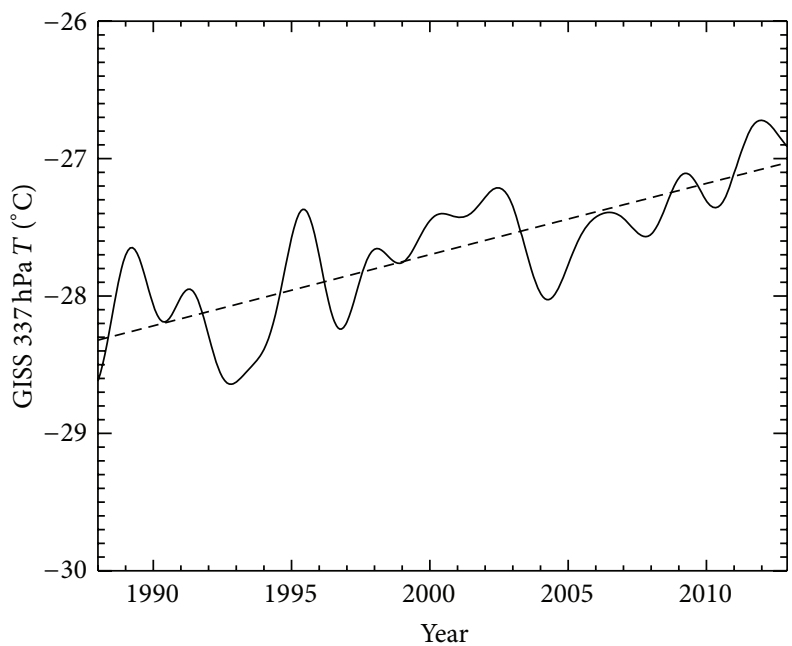

(d) $P<50 \mathrm{~mm} / \mathrm{mon}$.

FIgURE 4: Low-pass filtered time series for $337 \mathrm{hPa}$ temperature $(T)$ from GISS/HYCOM. (a) $T$ over high-precipitation area $(P>$ $200 \mathrm{~mm} / \mathrm{mon}$.) from the control simulation (solid line) and trend (dashed line). (b) $T$ over high-precipitation area from the historic simulation (solid line) and trend (dashed line). (c) Same as (a) except for areas with precipitation $<50 \mathrm{~mm} / \mathrm{mon}$. (d) Same as (b) except for areas with precipitation $<50 \mathrm{~mm} / \mathrm{mon}$.

the GISS/HYCOM historic model simulation. The residual vertical velocity displayed in Figure 6(a) has an increasing trend of $1.99 \pm 0.82 \mathrm{~m} /$ day/decade. Figure $6(\mathrm{~b})$ illustrates the residual vertical velocity of GISS/HYCOM control simulation. The residual vertical velocity for control simulation has a trend of $-0.04 \pm 0.68 \mathrm{~m} /$ day/decade. The historic simulation reveals a robust trend while the control simulation does not. The lack of an increasing trend in the control simulation is evidence of the influence anthropogenic forcing on the residual vertical velocity. The increasing trend demonstrated in the historic simulation suggests that an intensifying convection is occurring over the tropical region, and thus enhancing the precipitation in those regions. Such an intensifying convection is associated with a stronger meridional circulation, thus providing another perspective of the influence of the large-scale meridional circulation on the temporal variation of tropical precipitation.

\section{Conclusions}

The GISS model simulations imply that the anthropogenic forcing can affect the temporal variations of precipitation over the wet and dry areas. Results from the GISS historic simulation suggest that the wet area is getting wetter while the dry area is getting drier, which are consistent with the results from observation. Precipitation from the control simulation with fixed amounts of greenhouse gases and aerosols does not demonstrate trends over the wet and dry areas. The diagnostic studies of the simulations from the GISS models reveal that the atmospheric dynamics related to the convective stability, 


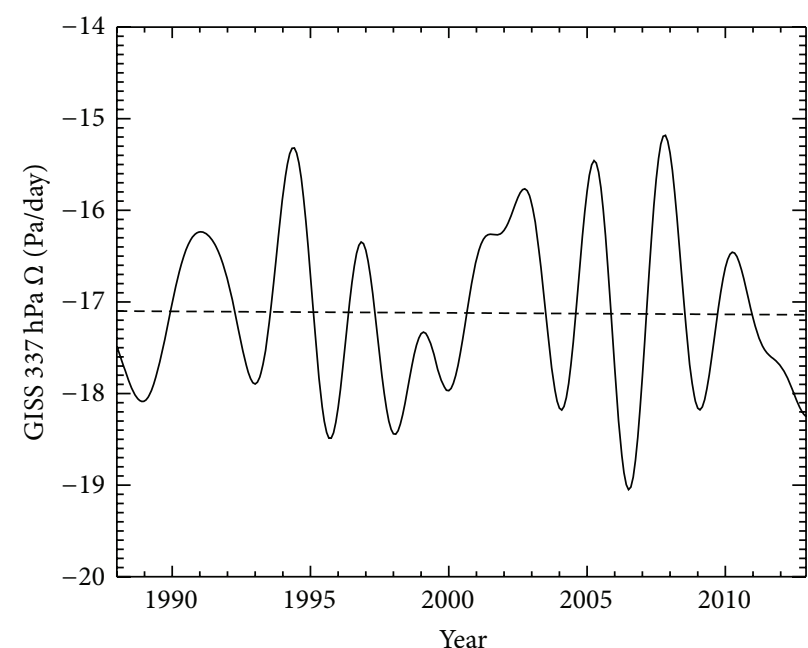

(a) $P>200 \mathrm{~mm} / \mathrm{mon}$.

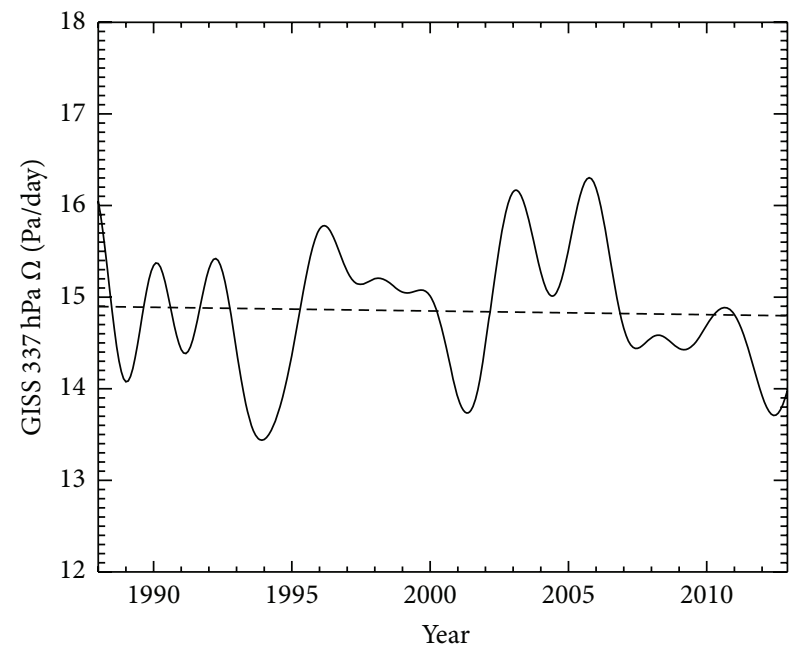

(c) $P<50 \mathrm{~mm} / \mathrm{mon}$.

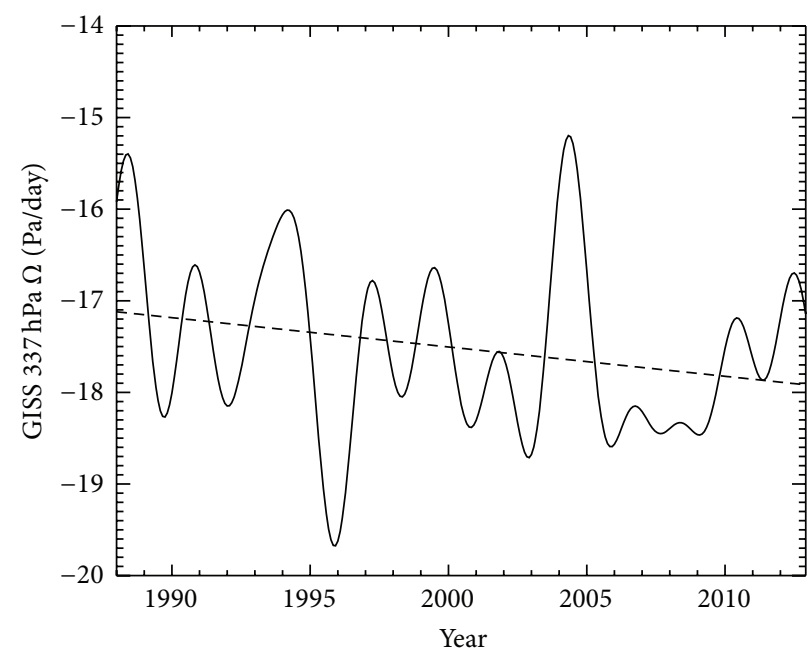

(b) $P>200 \mathrm{~mm} / \mathrm{mon}$.

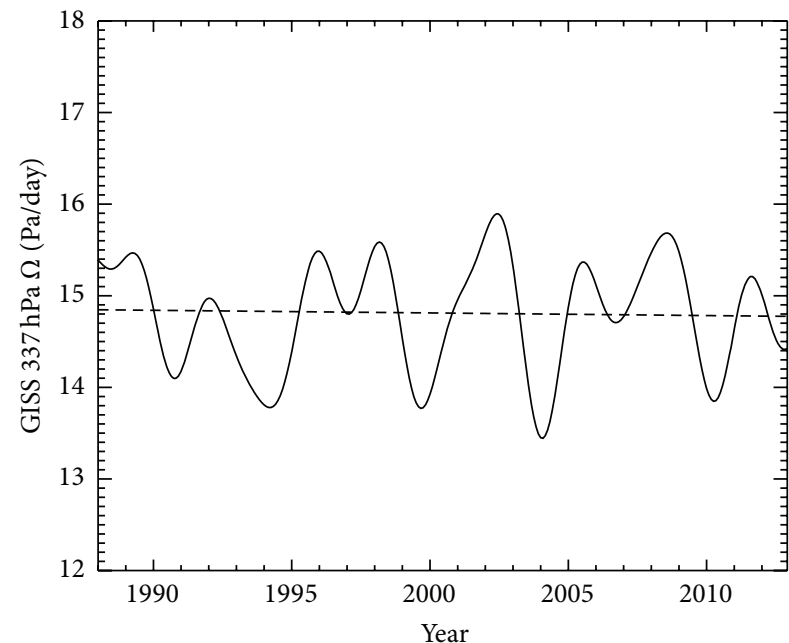

(d) $P<50 \mathrm{~mm} / \mathrm{mon}$.

FIGURE 5: Low-pass filtered time series for $337 \mathrm{hPa}$ vertical pressure velocity $\Omega(d P / d t)$ from GISS/HYCOM. (a) $\Omega$ over high-precipitation area $(P>200 \mathrm{~mm} / \mathrm{mon}$.) from the control simulation (solid line) and trend (dashed line). (b) $\Omega$ over high-precipitation area from the historic simulation (solid line) and trend (dashed line). (c) Same as (a) except for areas with precipitation $<50 \mathrm{~mm} / \mathrm{mon}$. (d) Same as (b) except for areas with precipitation $<50 \mathrm{~mm} / \mathrm{mon}$.

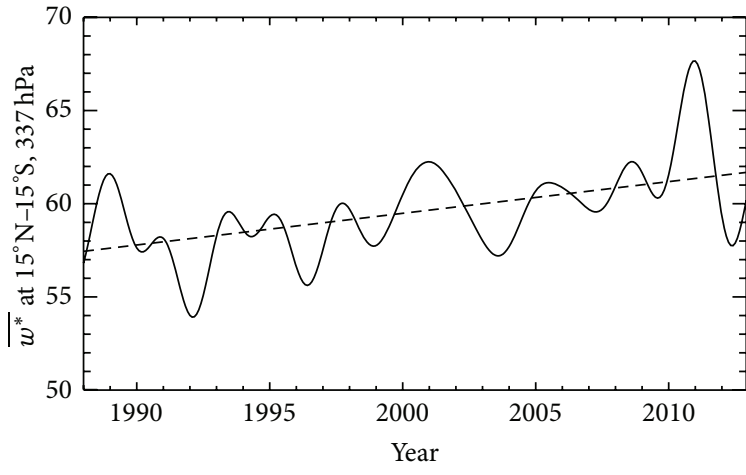

(a) GISS historic simulation

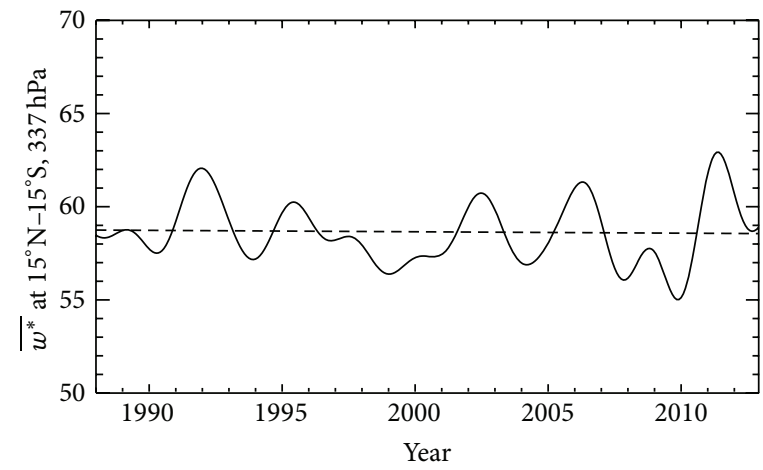

(b) GISS control simulation

Figure 6: (a) Residual vertical velocity $\left(\overline{w^{*}}\right)$ averaged over $15^{\circ} \mathrm{N}-15^{\circ} \mathrm{S}$ at $337 \mathrm{hPa}$ from historic simulation (solid line) and trend (dashed line). (b) Same as (a) except for control simulation. 
and hence the vertical motions, contribute to the increased precipitation over the wet area. Comparison of residual vertical velocity from the control and historic simulations also illustrates variations in meridional circulation as a result of global warming, which can further drive the increased precipitation over the tropical regions. Correct simulation of these important features by the climate model can help to elucidate the physics behind the temporal variations of precipitation, paving the way for more accurate prediction of future climate change due to anthropogenic activities.

With increasing numbers of weather extremes related to climate change, it is important to investigate precipitation, temperature, and water vapor trends and their associated spatial distribution. The significance and broader impacts are evident when we look at the consequences of increased drought in some areas and flooding in other areas. Droughts create a heightened threat for fire weather, diminishing the water supply, and recovery from the economic impact could take years. On the other hand, rapid and abundant rainfall could cause flooding and economic damages. These may be related to the influence of global warming.

\section{Conflict of Interests}

The authors declare that there is no conflict of interests regarding the publication of this paper.

\section{Acknowledgments}

The authors thank two anonymous reviewers for helpful comments. This work was supported by the NASA ROSES2010 NEWS Grant NNX13AC04G. Part of the research was carried out at the Jet Propulsion Laboratory, California Institute of Technology, under a contract with the National Aeronautics and Space Administration.

\section{References}

[1] R. E. Dickinson and R. J. Cicerone, "Future global warming from atmospheric trace gases," Nature, vol. 319, no. 6049, pp. 109-115, 1986.

[2] IPCC, Climate Change 2007: The Physical Science Basis, Cambridge University Press, Cambridge, UK, 2007.

[3] IPCC, Climate Change 2013: The Physical Science Basis, IPCC Secretariat, World Meteorological Organization, Geneva, Switzerland, 2013.

[4] K. E. Trenberth, J. Fasullo, and L. Smith, "Trends and variability in column-integrated atmospheric water vapor," Climate Dynamics, vol. 24, no. 7-8, pp. 741-758, 2005.

[5] B. D. Santer, C. Mears, F. J. Wentz et al., "Identification of human-induced changes in atmospheric moisture content," Proceedings of the National Academy of Sciences of the United States of America, vol. 104, no. 39, pp. 15248-15253, 2007.

[6] K. E. Trenberth and D. J. Shea, "Relationships between precipitation and surface temperature," Geophysical Research Letters, vol. 32, no. 14, Article ID L14703, 2005.

[7] R. F. Alder, G. J. Gu, J.-J. Wang, G. J. Huffman, S. Curtis, and D. Bolvin, "Relationships between global precipitation and surface temperature on interannual and longer timescales
(1979-2006)," Journal of Geophysical Research: Atmospheres, vol. 113, no. 22, Article ID D22104, 2008.

[8] R. P. Allan and B. J. Soden, "Atmospheric warming and the amplification of precipitation extremes," Science, vol. 321, no. 5895, pp. 1481-1484, 2008.

[9] S. C. Liu, C. B. Fu, C. J. Shiu, J. P. Chen, and F. T. Wu, "Temperature dependence of global precipitation extremes," Geophysical Research Letters, vol. 36, no. 17, Article ID L17702, 2009.

[10] L. Li, X. Jiang, M. T. Chahine et al., "The recycling rate of atmospheric moisture over the past two decades (1988-2009)," Environmental Research Letters, vol. 6, no. 3, Article ID 034018, 2011.

[11] S. Bony, G. Bellon, D. Klocke, S. Sherwood, S. Fermepin, and S. Denvil, "Robust direct effect of carbon dioxide on tropical circulation and regional precipitation," Nature Geoscience, vol. 6, no. 6, pp. 447-451, 2013.

[12] D. T. Shindell, G. Faluvegi, R. L. Miller, G. A. Schmidt, J. E. Hansen, and S. Sun, "Solar and anthropogenic forcing of tropical hydrology," Geophysical Research Letters, vol. 33, no. 24, 2006.

[13] K. Marvel and C. Bonfils, "Identifying external influences on global precipitation," Proceedings of the National Academy of Sciences of the United States of America, vol. 110, no. 48, pp. 19301-19306, 2013.

[14] R. F. Adler, G. J. Huffman, A. Chang et al., “The version-2 global precipitation climatology project (GPCP) monthly precipitation analysis (1979-present)," Journal of Hydrometeorology, vol. 4, no. 6, pp. 1147-1167, 2003.

[15] G. J. Gu, R. F. Adler, G. J. Huffman, and S. Curtis, "Tropical rainfall variability on interannual-to-interdecadal and longer time scales derived from the GPCP monthly product," Journal of Climate, vol. 20, no. 15, pp. 4033-4046, 2007.

[16] M. R. Allen and W. J. Ingram, "Constraints on future changes in climate and the hydrologic cycle," Nature, vol. 419, no. 6903, pp. 224-232, 2002.

[17] I. M. Held and B. J. Soden, "Robust responses of the hydrological cycle to global warming," Journal of Climate, vol. 19, no. 21, pp. 5686-5699, 2006.

[18] G. L. Stephens and T. D. Ellis, "Controls of global-mean precipitation increases in global warming GCM experiments," Journal of Climate, vol. 21, no. 23, pp. 6141-6155, 2008.

[19] C. Chou and J. D. Neelin, "Mechanisms of global warming impacts on regional tropical precipitation," Journal of Climate, vol. 17, no. 13, pp. 2688-2701, 2004.

[20] R. P. Allan and B. J. Soden, "Large discrepancy between observed and simulated precipitation trends in the ascending and descending branches of the tropical circulation," Geophysical Research Letters, vol. 34, no. 18, Article ID L18705, 2007.

[21] C. Chou, J. D. Neelin, C.-A. Chen, and J.-Y. Tu, "Evaluating the 'rich-get-richer' mechanism in tropical precipitation change under global warming," Journal of Climate, vol. 22, no. 8, pp. 1982-2005, 2009.

[22] P. J. Durack, S. E. Wijffels, and R. J. Matear, “Ocean salinities reveal strong global water cycle intensification during 1950 to 2000," Science, vol. 336, no. 6080, pp. 455-458, 2012.

[23] D. Polson, G. C. Hegerl, R. P. Allan, and B. B. Sarojini, "Have greenhouse gases intensified the contrast between wet and dry regions?" Geophysical Research Letters, vol. 40, no. 17, pp. 47834787, 2013. 
[24] C. Chou, J. C. H. Chiang, C.-W. Lan, C.-H. Chung, Y.-C. Liao, and C.-J. Lee, "Increase in the range between wet and dry season precipitation," Nature Geoscience, vol. 6, no. 4, pp. 263-267, 2013.

[25] M.-C. Liang, L.-C. Lin, K.-K. Tung, Y. L. Yung, and S. Sun, "Impact of climate drift on twenty-first-century projection in a coupled atmospheric-ocean general circulation model," Journal of the Atmospheric Sciences, vol. 70, no. 10, pp. 3321-3327, 2013.

[26] G. J. Huffman, R. F. Adler, P. Arkin et al., "The global precipitation climatology project (GPCP) combined precipitation dataset," Bulletin of the American Meteorological Society, vol. 78, no. 1, pp. 5-20, 1997.

[27] G. J. Huffman, D. T. Bolvin, and R. F. Adler, GPCP Version 2.2 Combined Precipitation Data Set, NCDC, Asheville, NC, USA, 2012.

[28] R. P. Allan, B. J. Soden, V. O. John, W. Ingram, and P. Good, "Current changes in tropical precipitation," Environmental Research Letters, vol. 5, no. 2, Article ID 025205, 2010.

[29] D. E. Waliser and C. Gautier, "A satellite-derived climatology of the ITCZ," Journal of Climate, vol. 6, no. 11, pp. 2162-2174, 1993.

[30] X. Jiang, J. Wang, E. T. Olsen et al., "Influence of EL Niño on midtropospheric $\mathrm{CO}_{2}$ from Atmospheric infrared sounder and model," Journal of the Atmospheric Sciences, vol. 70, no. 1, pp. 223-230, 2013.

[31] X. Jiang, C. D. Camp, R. Shia, D. Noone, C. Walker, and Y. L. Yung, "Quasi-biennial oscillation and quasi-biennial oscillation-annual beat in the tropical total column ozone: a twodimensional model simulation," Journal of Geophysical Research D: Atmospheres, vol. 109, no. 16, 2004.

[32] P. R. Bevington and D. K. Robinson, Data Reduction and Error Analysis for the Physical Sciences, McGraw-Hill, New York, NY, USA, 3rd edition, 2003.

[33] C. S. Bretherton, M. Widmann, V. P. Dymnikov, J. M. Wallace, and I. Bladé, "The effective number of spatial degrees of a time varying field," Journal of Climate, vol. 12, no. 7, pp. 1990-2009, 1999.

[34] G. J. Gu and R. F. Adler, "Interdecadal variability/long-term changes in global precipitation patterns during the past three decades: global warming and/or pacific decadal variability?" Climate Dynamics, vol. 40, no. 11-12, pp. 3009-3022, 2013.

[35] M. Salby, Physics of the Atmosphere and Climate, Cambridge University Press, 2012. 

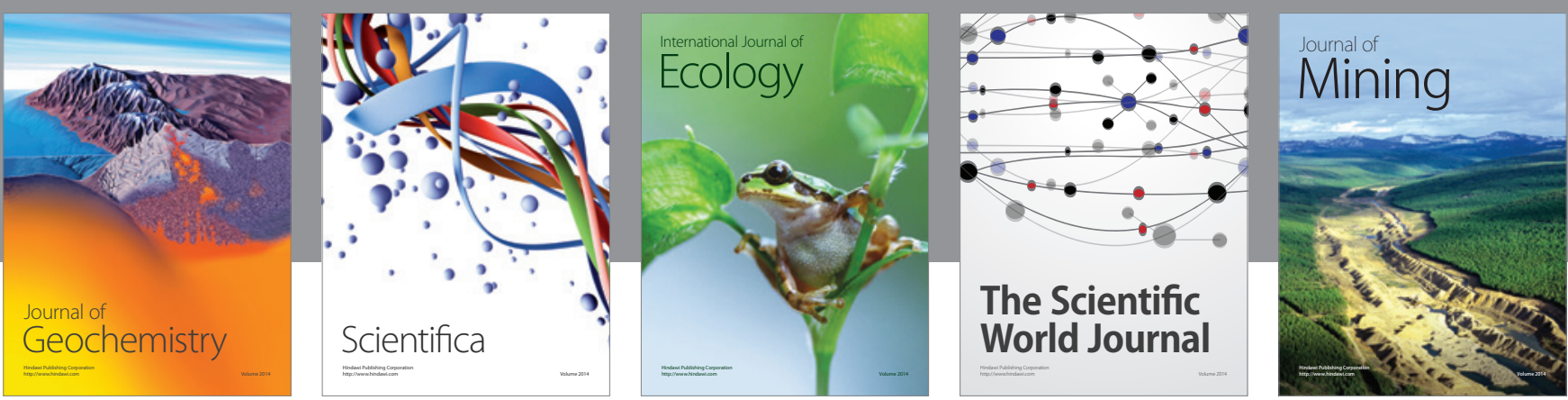

The Scientific World Journal
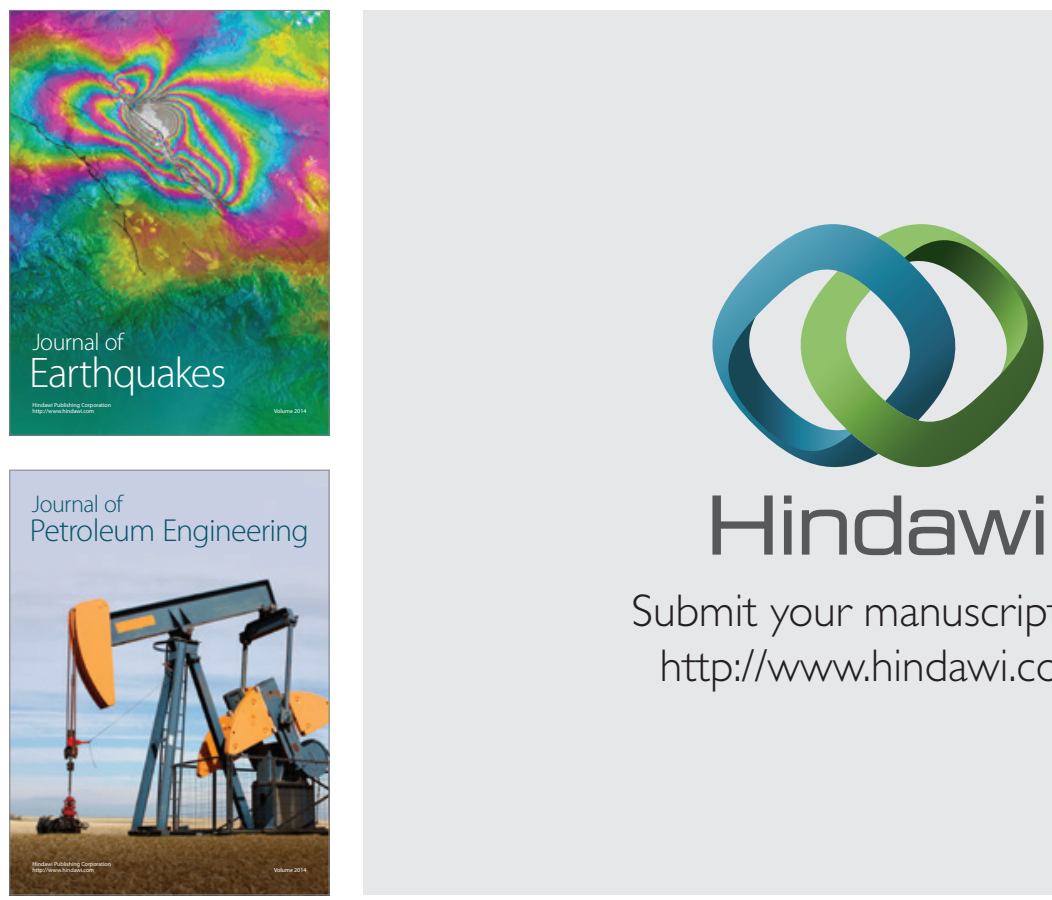

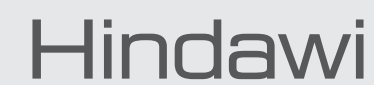

Submit your manuscripts at

http://www.hindawi.com
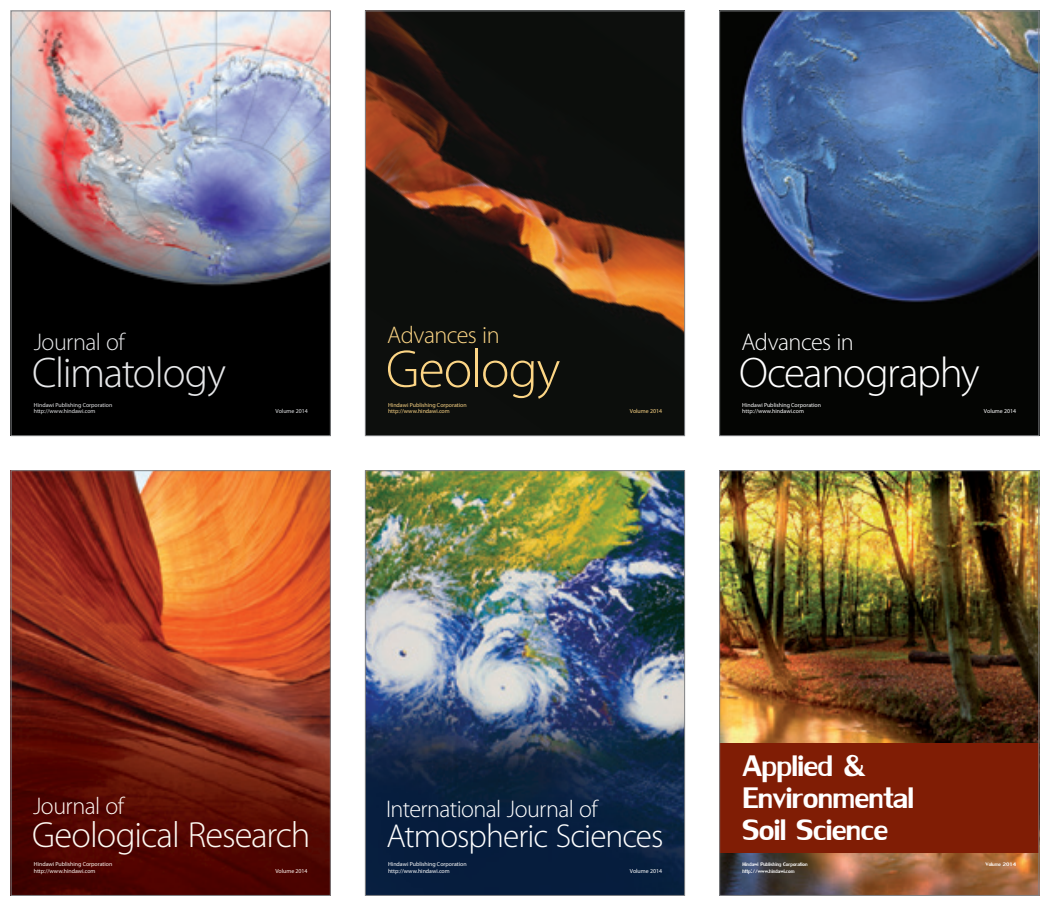
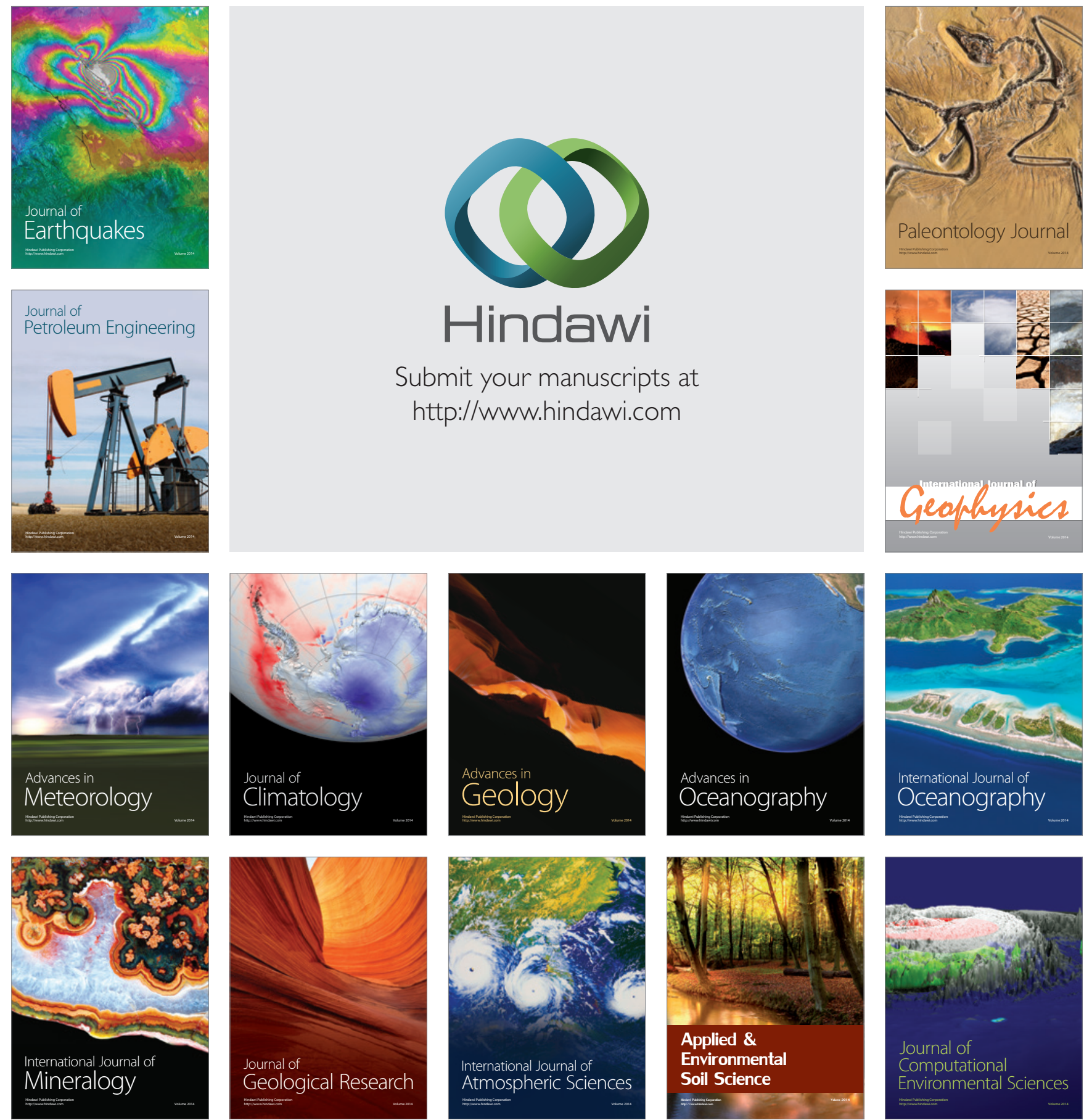